\title{
La persistencia de los monopolios: la exhibición de cine y la televisión bajo el PRI, 1938-19931
}

The Persistence of Monopolies: Film Exhibition and Television under the PRI, 1938-1993

\section{Andrew}

Paxman

Centro de Investigación

y Docencia Económicas,

CIDE, México

\footnotetext{
1 El autor quisiera agradecer a los dos dictaminadores anónimos por sus comentarios y a Luis Barrón por traducir la primera versión del artículo. Cualquier infortunio estilístico es mío.
}

Recibido: 28 de octubre de 2020.

Aprobado: 1 de diciembre de 2020. 


\section{Resumen}

Desde la Revolución, el Estado mexicano buscó fortalecer el principio antimonopólico establecido en la Constitución. Sin embargo, casi siempre hacía caso omiso de las nuevas reglas, prefiriendo dejar que los monopolios florecieran. Este artículo ofrece una explicación holística, pues argumenta que los monopolios persistían debido a cuatro razones básicas, dos económicas y dos políticas. Primero y más importante, la clase dirigente buscaba acuerdos con la élite empresarial, basados en una percibida necesidad mutua. Segundo, esta práctica iba acompañada, sobre todo a partir de los años cuarenta, por intercambios de favores entre políticos e industriales. Tercero, la naturaleza corporativista del partido gobernante favorecía relaciones con un número limitado de interlocutores. Cuarto, el estilo personalista del presidencialismo mexicano favorecía relaciones directas con magnates. Para ilustrar cómo operaban estos factores, se presentan dos estudios de caso: (i) el monopolio de exhibición de cine de William Jenkins en los años cuarenta y cincuenta; (ii) el monopolio televisivo de la familia Azcárraga entre 1955 y 1993.

Palabras clave: monopolios, Estado, gobierno, capitalismo, élites.

Clasificación JEL: L12, L41, N46, N76.

\section{Abstract}

As of the Revolution, the Mexican state sought to bolster the anti-monopoly principle of the Constitution. However, it almost always ignored its new rules, preferring to let monopolies flourish. This article offers a holistic explanation, by arguing that monopolies persisted for four chief reasons, two economic and two political. First and most importantly, the political establishment sought accords with the business elite, based on a perceived mutual necessity. Second, this practice was accompanied, especially as of the 1940s, by exchanges of favor between politicians and businessmen. Third, the corporatist nature of the ruling party favored dealings with a limited number of interlocutors. Fourth, the personalistic style of Mexican presidentialism favored direct dealings with magnates. To illustrate how these factors operated, two case studies are presented: (i) the film exhibition monopoly of William Jenkins in the 1940s and 1950s; (ii) the television monopoly of the Azcárraga family between 1955 and 1993.

Keywords: monopolies, state, government, capitalism, elites.

JEL Classification: L12, L41, N46, N76. 


\section{Introducción}

En la economía mexicana los monopolios han sido un aspecto común y en cierta medida oficialmente permitido o aun fomentado desde finales del siglo XVIII (DeansSmith, 1992: cap. 1; Concheiro, Gutiérrez y Fragoso, 1979). Como una de las metas de la Revolución fue deshacer o por lo menos atemperar las grandes concentraciones de la riqueza, después de la guerra el Estado buscó fortalecer las políticas antimonopólicas del siglo XIX, primero robusteciendo el lenguaje relevante del art. 28 de la Constitución de 1857, que fue emendado en la de 1917, y luego promulgando leyes reglamentarias, de las cuales la más comprensiva fue la de 1934 (Ley Federal de Competencia Económica, LFCE, 2006: «Antecedentes históricos»). Esta ley prohibió «la existencia de monopolios» (art. 1) y los definió como toda empresa que deliberadamente permite la imposición de precios o tarifas con perjuicio del consumidor (art. 3; Ley Orgánica del Artículo 28 Constitucional en materia de Monopolios, 1934). ${ }^{2}$ Sin embargo, casi siempre se hacía caso omiso a la ley, ya que el Estado prefería dejar que los nuevos monopolios florecieran. Según un experto legal, antes de que fuera reemplazada por la Ley Federal de Competencia Económica (1992), la ley de 1934 fue aplicada solo una vez en contra de un infractor (Pérez Miranda, 1999: 284). Desde 1992, reguladores, fallos judiciales y nuevas leyes han limitado de manera moderada a empresas preponderantes como Telmex (OCDE, 2017). Sin embargo, el legado de los acuerdos históricos entre el Estado y el capital permanece, ya que en el ámbito empresarial solo uno o dos actores grandes siguen dominando sectores como el de la cerveza, el pan, la harina de maíz, los cigarrillos, el cemento y la televisión abierta, además de la telefonía.

A diferencia de estudios existentes que dan explicaciones únicas o limitadas del fracaso de los gobiernos posrevolucionarios para prohibir los monopolios, este artículo ofrece una explicación holística, es decir, considera en conjunto las perspectivas económicas, políticas y culturales. Los monopolios se desarrollaron y persistieron debido a cuatro factores principales, dos económicos y decisivos, dos políticos y complementarios. De la mayor importancia, la clase política dirigente, en especial durante su época de debilidad económica en las décadas de 1920 y 1930, se consideró

\footnotetext{
2 Como lo nota el citado preámbulo a la ley de 2006, esa definición era «cuestionable» y la ley no contempló sanciones penales que castigaban prácticas anticompetitivas, lo que en conjunto sugiere una falta de voluntad política de enfrentar los monopolios que ya se estaban formando.
} 
obligada a buscar acuerdos formales con la élite empresarial que, a su vez, se sintió presionada por las promesas radicales de la Constitución de 1917, y así dio la bienvenida a las propuestas del gobierno. Este sentido de necesidad mutua persistió en los años cuarenta y después, ya que la élite política seguía sensible a cualquier desafío a su hegemonía, y la élite empresarial —ante la ausencia de leyes claras, tribunales imparciales y reguladores autónomos- reconocía su necesidad de amigos en las altas esferas. Segundo, este fenómeno iba acompañado, especialmente a partir de los años cuarenta, por muchos intercambios informales de favores económicos entre individuos políticos y empresariales. Tercero, la naturaleza corporativista del Partido Revolucionario Institucional, PRI, a partir de 1938, favorecía tratos con un número limitado de interlocutores, incluso entre la clase empresarial. Cuarto, el estilo personal del presidencialismo mexicano favorecía tratos interpersonales con los magnates en vez de reuniones con los líderes de las asociaciones o las cámaras de comercio, que usualmente eran empresarios de nivel intermedio.

Para ilustrar la mecánica e interacción de estos factores, este artículo estudia dos casos en que los actores estatales facilitaron la fundación o expansión de monopolios: el imperio de la exhibición de cine del industrial expatriado estadounidense William Jenkins y sus socios en los años cuarenta y cincuenta, y el monopolio de TV abierta que encabezaron Emilio Azcárraga Vidaurreta y su hijo Emilio Azcárraga Milmo entre 1955 y 1993, el cual ha perdurado en forma cuasimonopólica hasta hoy. Mientras los historiadores y comunicólogos han estudiado estas dos empresas de manera separada (Águila, Soler y Suárez, 2007; Paxman, 2016; Mejía Barquera, 1989; Saragoza, 1991; González de Bustamante, 2015), nadie lo ha hecho de forma comparada. Hay que admitir que las dos industrias seleccionadas comparten la característica peculiar de poder ofrecer al Estado apoyos propagandísticos además de favores de otro tipo. Se necesita más investigación para determinar hasta dónde los monopolios no mediáticos forman el modelo de interdependencia descrito aquí.

\section{Las relaciones Estado-capital: la historiografía y sus lagunas}

Los estudios de las relaciones Estado-capital en México han tendido a padecer perspectivas limitadas por ideología, disciplina o la falta de acceso a fuentes. Cuando los científicos sociales primero tocaron el tema de la élite económica mexicana y cómo su riqueza se quedaba altamente concentrada a pesar de la Revolución, lo hicieron 
sobre todo desde una perspectiva marxista y/o dependentista. La mayor parte de tales obras asumió que todos los industriales de México eran reaccionarios, parásitos y explotadores de obreros, y que la mayoría estaban subordinados a los inversionistas extranjeros (Ceceña, 1963; Aguilar y Carmona, 1967; Leal, 1972; Concheiro, Gutiérrez y Fragoso, 1979; Basáñez, 1981; Hamilton, 1982). Estos textos, que tendían a privilegiar certidumbres ideológicas sobre evidencias archivísticas u orales (Cerutti, 1999: 117), interpretaron la persistencia posrevolucionaria de grandes empresas como el producto de la hegemonía estadounidense y la limitada autonomía del Estado mexicano. En la relación Estado-capital, era la «gran burguesía» que se había impuesto, y el culpable principal no era el gobierno sino el capitalismo internacional.

Después de la nacionalización bancaria de 1982, los estudios sobre el empresariado mexicano divergieron. En México, el marco dominante tendía a contraponer un Estado reformista en conflicto con una iniciativa privada reaccionaria. Las épocas de armonía Estado-capital (1940 a 1958, 1964 a 1970) eran atribuibles a una falta de visión revolucionaria y/o a la fuerza del capital internacional (Martínez Nava, 1984; Jacobo, Luna y Tirado, 1989). En los noventa, el tono ideológico disminuyó, pero algunos académicos aún se interesaban más que nada por el tema de quién lograba imponerse en la cambiante relación Estado-capital, en vez de por la complicidad del Estado en las prácticas monopólicas (Valdés Ugalde, 1997). Los estudios de caso se volvieron analíticamente más sofisticados, aunque solo una minoría exploró cómo empresas individuales se beneficiaron de relaciones cercanas con actores estatales (Romero, Contreras Valdez y Reyes, 2006).

En Estados Unidos, una nueva generación de investigadores cuestionó el viejo dogma marxista-dependentista. Los historiadores que estudiaron el período desde el porfiriato a 1940 con un enfoque en la persistencia de las élites, al estudiar registros archivísticos descubrieron que las élites empresariales habían dependido menos de Estados Unidos y habían sido algo más emprendedoras de lo que se supuso anteriormente (Saragoza, 1988; Haber, 1989; Wasserman, 1993). Los politólogos entrevistaron a líderes empresariales y llegaron a conclusiones parecidas en cuanto a la época posterior a 1940 (Story, 1986; Camp, 1989). Tales obras enfatizaron los compromisos del Estado posrevolucionario, establecidos tanto con selectas élites porfirianas como con nuevas clases de emprendedores, en pos de consolidar el control político y luego dirigir el desarrollo económico. Este trabajo mostró evidencias de favoritismos hacia ciertos industriales, pero como su enfoque se trataba o de la formación estatal (en las historias) o de la limitada influencia política de la iniciativa privada (Story, 1986; Camp, 1989), no hubo un intento sistemático de explicar 
la persistente concentración de capital. La excepción fue Industry and Underdevelopment (Industria y subdesarrollo) de Stephen Haber (1989), la primera historia que revisó los archivos de múltiples compañías mexicanas. Haber halló que la concentración de capital se debía mucho a una interdependencia mutua entre élites políticas y económicas. Estas últimas ofrecieron no solo progreso industrial y la creación de empleo, sino el acceso a prestamistas internacionales.

Si el estudio de Haber marcó un parteaguas probatorio, su siguiente libro le prestó al asunto de las ineficiencias económicas un marco teórico: la New Institutional Economics (Haber, 1997). Este tomo colaborativo argumentó que la economía mexicana había quedado muy atrás de la de Estados Unidos durante el siglo XIX, principalmente por la debilidad de sus instituciones legales. Inversionistas potenciales rara vez tenían la certeza de que sus inversiones gozarían de la protección legal, o de la expropiación arbitraria, de impuestos punitivos o de rivales políticamente favorecidos. En tomos posteriores, Haber y sus coautores argumentarían que el Estado mexicano, antes y después de la Revolución, compensó estas debilidades por el mecanismo del crony capitalism (capitalismo de amigos). Esto lo definieron como «un sistema en el cual los que están más cercanos a las autoridades políticas, que hacen y ejecutan las políticas, reciben favores que tienen gran valor económico» (Haber, 2002: xii). En este caso, los inversionistas dispuestos a formar sociedades con miembros de la clase dirigente recibieron así la garantía de que no correrían los riesgos ni de la expropiación, ni de los impuestos punitivos ni de rivales favorecidos. Esta práctica empezó en el porfiriato y emergió con actores en su mayoría nuevos en la década de 1920 (Bortz y Haber, 2002; Haber, 2002; Haber, Razo y Maurer, 2003).

Haber y su cohorte han arrojado mucha luz sobre la evolución de prácticas rentistas en México, pero su trabajo no explica el florecimiento de monopolios durante el resto del siglo XX. Primero, está limitado por su período. Como la mayoría de las historias empresariales de México, rara vez mira más allá de 1930. Segundo, su obra está restringida por su enfoque en el Estado como institución, con sus políticas y prioridades colectivas; presta poca atención a los actores estatales individuales (presidentes, ministros, gobernadores), que en sus tratos con las élites empresariales podían tener menos interés en una exitosa implementación de políticas que en el enriquecimiento propio. Las prácticas corruptas de políticos y altos funcionarios se volvieron más visibles a partir de los años cuarenta y persistieron durante todo el siglo XX (Niblo, 1995 y 1999; Morris, 1991).

Una limitación relacionada es la naturaleza nebulosa del mismo término crony capitalism. Mientras Haber lo usa para describir un arreglo mutuamente benéfico entre 
el Estado y empresas o sectores privados, la etiqueta se emplea de manera más popular para describir acuerdos cómodos a nivel interpersonal. Además, el término tiende a despreciar a ciertos capitalistas como rentistas privilegiados, dicotomizándolos frente a emprendedores trabajadores como si un industrial no pudiera ser ambas cosas en distintos momentos.

Una nueva taxonomía podría ser, por lo tanto, útil. Como Haber y otros han mostrado, los acuerdos a nivel institucional fueron principalmente una cuestión de necesidad. Entre 1920 y 1940, los líderes políticos de México buscaban la asistencia de la iniciativa privada para reconstruir la economía, obtener acceso a préstamos internacionales y fortalecer al Estado tras una guerra civil de diez años, mientras la élite empresarial buscaba el compromiso federal para restaurar el orden, construir caminos, domar al sector laboral radicalizado, hacer cumplir los derechos de propiedad y promulgar leyes que suavizarían el radicalismo de la Constitución de 1917 en cuanto a derechos laborales, la expropiación de activos y otros asuntos. Así, la dinámica que impulsaba a ambas partes a una interdependencia de beneficio mutuo podría ser llamada una «simbiosis imperativa», es decir, un acuerdo institucional, formal y visible, basado en necesidades percibidas y el bien común. El ejemplo más obvio de esto fue la alianza del Estado con la banca, que perduró desde los años veinte hasta 1982 (Maurer, 2002). Luego, a partir de los años cuarenta, mientras el poder federal centralizado y la hegemonía electoral del PRI consolidaron estos arreglos institucionales, aunque nunca desaparecieron, se vieron igualados, si no superados en importancia económica, por tratos «crony» (de amiguismo) entre individuos. Aquí la dinámica podría ser llamada una «simbiosis conveniente», es decir, un arreglo interpersonal, informal y usualmente encubierto, principalmente basado en la avaricia. Debido a que tiende a privar al gobierno de impuestos y a evitar la asignación eficiente del gasto público, así como a quitarle oportunidades de precios justos a rivales empresariales y a consumidores, esta simbiosis generalmente socava el bien común. Incluye favores tales como sociedades encubiertas, contratos otorgados sin licitación, la aplicación selecta de leyes y reglamentos, fallos legales perjudiciales o la negación de concesiones a competidores. ${ }^{3}$

Finalmente, y de nuevo debido a sus límites de periodización, la obra de Haber y su cohorte omite dos características clave del Estado mexicano que animarían aún más el desarrollo de monopolios a partir de los años treinta: el corporativismo y,

3 Profundizo los términos "simbiosis imperativa" y "simbiosis conveniente" en la introducción de Paxman, 2017. 
especialmente, el personalismo presidencialista. Cuando el Partido Nacional Revolucionario fue transformado por Lázaro Cárdenas en el Partido de la Revolución Mexicana en 1938, revistió una naturaleza corporativista, cuyos pilares constituyentes eran los obreros, el campesinado y los empleados públicos. Aunque la iniciativa privada estuviera formalmente excluida de la estructura del PRM, la Ley de Cámaras de 1936 obligó a las empresas a afiliarse con la cámara de comercio de su sector, todas las cuales se volvieron ramas semioficiales del Estado corporativista y, por lo tanto, estaban sujetos a un grado de control federal (Saragoza, 1988). Una parte de la razón de ser de un Estado corporativista es facilitar el proceso de gobernar al establecer un interlocutor clave por sector, para poder equilibrar los intereses rivales con más facilidad. Para negociar con los sindicalizados, o la mayoría de estos, el presidente o el secretario del Trabajo solo tenía que hablar con el secretario general de la Confederación de Trabajadores de México (CTM). Para comunicarse con el campesinado, bastaba una llamada al presidente de la Confederación Nacional Campesina (CNC). Sin embargo, durante las décadas subsecuentes, las presidencias rotatorias de las cámaras de comercio y las asociaciones empresariales voluntarias fueron usualmente ocupadas no por los dueños o directores generales de las empresas mayores, sino por industriales de rango intermedio (Camp, 1989: 144-155). Como lo confirman biografías y memorias empresariales, los magnates más ricos y poderosos preferían hablar con el presidente y los miembros de su gabinete en persona (Ortiz Rivera, 1997; Espinosa Yglesias, 2000; Fernández y Paxman, 2013). El presidente y sus ministros, por su parte, estuvieron por lo general dispuestos a reunirse con ellos. Para 1980, el consenso entre la iniciativa privada era que la influencia de unos cuantos industriales destacados era mayor que la de las cámaras (Story, 1986).

El tono de tal personalismo presidencial fue sentado en los años veinte por Álvaro Obregón que, a diferencia de su antecesor, Venustiano Carranza (pero como Porfirio Díaz), a menudo concedió audiencias a miembros de la élite empresarial o a sus representantes. También centralizó el poder, debilitó los partidos políticos y revivió la tradición de seleccionar a su sucesor. Cárdenas amplió la autoridad presidencial y presidentes subsecuentes, notablemente Miguel Alemán, cultivaron un estilo no solo autocrático sino personalista. Los Pinos se volvió una corte a la cual se mandaba a llamar los líderes de sectores y empresas o se les admitía a petición. Tal gobernanza presidencialista (aunque cada vez de más mala fama después de 1968) persistiría hasta el sexenio de Carlos Salinas (Cosío Villegas, 1972; Garrido, 1989; Krauze, 1996). 
El corporativismo y el personalismo presidencialista se combinaban así para facilitar el auge de los monopolios al fomentar una cultura política en la cual los líderes trataban directamente con los líderes. Si Alemán quería suprimir una película o promover un noticiero, solo tenía que hacer una llamada a Jenkins en Puebla. Si Adolfo Ruiz Cortines quería que un nuevo programa del gobierno tuviera extensa cobertura en noticieros televisivos, podía invitar a Azcárraga Vidaurreta a comer. Y en 1993, cuando Salinas quiso «modernizar» las finanzas del PRI para sustituir la dependencia del erario con cooperaciones privadas, convino una cena de magnates, la mayoría de quienes representaban un sector en el cual tenían un monopolio o duopolio, y el presidente del partido les pidió 25 millones de dólares a cada uno.

\section{Caso 1: William Jenkins y la exhibición de cine}

William Jenkins, expatriado estadounidense, se instaló en la ciudad de Puebla en 1906 e hizo fortunas consecutivas en bonetería, bienes raíces durante la Revolución, azúcar y alcohol durante los años veinte y treinta. En cada caso cultivó nexos con políticos locales, sobre todo gobernadores del estado, para cuidar sus intereses y encubrir sus actividades monopólicas. Este arreglo alcanzó una máxima eficiencia de interdependencia cuando Jenkins patrocinó la campaña gubernamental y subsidió el gobierno de Maximino Ávila Camacho (1937-1941), quien a cambio protegió Atencingo, su gran ingenio azucarero, de un intento expropiador del presidente Cárdenas (Paxman, 2016, 2017).

Tras este intento, el estadounidense diversificó sus activos, incluso en la construcción y compra de cines en Puebla, donde pronto acaparó el mercado. En los años cuarenta y cincuenta, junto con varios socios mexicanos, Jenkins erigió un cuasimonopolio de la exhibición de cine a nivel nacional y una posición fuerte, si no líder, en el financiamiento de películas. Trabajaba de manera separada con socios distintos, principalmente Manuel Espinosa Yglesias y Gabriel Alarcón. El norteamericano invertiría todo o la mayoría del capital necesario para construir cada teatro, pero solo se quedaría con una participación de $50 \%$; sus socios le reembolsarían la suma equivalente a su propio 50 \% desde su porción de las futuras utilidades (Águila, Soler y Suárez, 2007).

Mientras crecían los circuitos de cines de Espinosa y Alarcón, y competían entre sí, el hecho de que tuvieran dueños y gerencias distintas ayudó a evitar la apariencia de un monopolio. Para ser correcto, el negocio era menos un monopolio que un 
monopsonio. La colusión entre los dos — bajo la supervisión de Jenkins - en la renta de películas de los distribuidores hollywoodenses y nacionales y en financiar producciones locales redujo sus costos, lo que mantenía sus utilidades artificialmente altas (Águila, Soler y Suárez, 2007; Paxman, 2016).

Desde el inicio, el llamado Grupo Jenkins usaba prácticas monopólicas para subyugar a sus rivales. La palanca que tenía sobre los distribuidores era clave; explica, por ejemplo, cómo Jenkins forzó a Azcárraga a vender su Cadena de Oro de 20 salas. Espinosa Yglesias les avisó a los productores mexicanos y a los agentes hollywoodenses que si seguían surtiendo al Cine Alameda, el teatro principal de Azcárraga, él rehusaría proyectar sus películas en la capital, Puebla, Veracruz y todos los demás mercados donde se estaba convirtiendo en líder. Como resultado, Azcárraga se encontró sin más opción que proyectar películas inferiores. Tras un largo período de pérdidas, Azcárraga vendió su circuito al Grupo Jenkins (Paxman, 2016).

Sin poder contar con circuitos comparables para convencer a los distribuidores de que les ofrecieran precios equivalentes, los exhibidores rivales poco a poco se vendieron a Jenkins. En 1958, un perfil del Grupo Jenkins mostró lo extenso de su imperio. El circuito COTSA de Espinosa y sus empresas afiliadas tenían o arrendaban 900 cines en todo México. La Cadena de Oro de Alarcón y sus filiales tenían o arrendaban unos 700. Solo unos 400 teatros se mantenían independientes (Paxman, 2016).

El dominio del Grupo Jenkins era un fenómeno curioso. ¿Por qué un Estado que se asumía revolucionario le permitió crecer y perdurar, a pesar de la ley antimonopolio de 1934? ¿Y cómo fue posible que el monopolio fuera controlado por un ciudadano estadounidense, a pesar de una prohibición de 1945 de que los extranjeros tuvieran posesión mayoritaria de activos cinematográficos? (Niblo, 1995). ${ }^{4}$

Primero, Jenkins y el Estado asumieron un nexo interdependiente, basado en necesidades mutuas. El gobierno permitió una concentración monopólica de activos en las manos de un estadounidense a cambio del compromiso del Grupo Jenkins de expandir el entretenimiento para los crecientes millones de mexicanos, animando así su aculturación urbana y su unificación nacional. El Grupo Jenkins lo haría por construir, o comprar y remodelar, cientos de cines y usarlos para la proyección de

4 Un decreto de la Secretaría de Relaciones Exteriores de abril de 1945 especificó que el cine era uno de los sectores cuyas empresas no podían ser exentos de la llamada «ley del 51 \%» de 1944. Esta prohibición pudo haber constituido otro factor a favor de Jenkins, por obstaculizar la entrada de las cadenas de cines estadounidenses en el mercado mexicano de la exhibición. 
películas que levantaron la moral, y noticieros que halagaron al gobierno. Por supuesto, los rivales de Jenkins hacían lo mismo, pero ninguno se pudo expandir tan rápido. La construcción de cines era un negocio altamente intensivo en capital, así que solo los inversionistas más ricos pudieron construir una cadena entera, y pudieron acelerar su expansión si se permitían las prácticas monopólicas, sacando a sus rivales del negocio. Al segundo mayor dueño de cines de México, el expresidente Abelardo L. Rodríguez, le fue permitido construir un cuasimonopolio regional en el noroeste. En su momento se estimó que el Grupo Jenkins había construido entre 200 y 300 cines, y comprado y remodelado muchos más (Paxman, 2016).

Durante los años cuarenta, el Estado tenía dos grandes preocupaciones que se relacionaban entre sí: la paz laboral y la cohesión social. La paz laboral era una preocupación debido a la alta inflación que resultó de la guerra y la posguerra; el sexenio de Ávila Camacho atestiguó un número inédito de huelgas (Middlebrook, 1995). A la vista del Estado, el cine proveía «circo al pueblo», entretenimiento barato para las masas; también suministraba el vehículo propagandístico de los noticieros, que se proyectaban antes de la función principal. La cohesión social era una preocupación debido al influjo de millones de personas provenientes del campo a las ciudades durante la industrialización del país. El cine hollywoodense y el cine mexicano conservaban los valores familiares y las «buenas costumbres», y fomentaban el consumismo. El cine mexicano, en lo particular, también propiciaba una relación estable entre ricos y pobres e inculcaba sentimientos de orgullo nacionalista (Monsiváis, 1994; Noble, 2005). La creencia del Estado en el potencial unificador del cine es evidente en una propuesta de ley que Ávila Camacho envió al Congreso: la exposición de motivos señaló la capacidad del cine nacional de fomentar «sentimientos de unidad y cohesión» (Ávila Camacho, 1946). En suma, el Estado necesitaba al Grupo Jenkins para facilitar metas específicas de política pública. El Grupo Jenkins necesitaba al Estado como escudo frente a obreros radicalizados (a diferencia de otros sectores, las huelgas rara vez ocurrieron en sus cines); para eximirlo de los límites sobre accionistas extranjeros; para protegerlo de la amenaza del estatuto antimonopolio de $1934 .^{5}$

Segundo, la interdependencia fue fortalecida por intercambios de favores a nivel individual. Justo como el Grupo Jenkins nació en Puebla, también se originaron allí

5 En cuanto a la ley de 1934, vale notar que aunque casi nunca fue aplicada para romper un monopolio, su mera existencia habrá fortalecido la capacidad del Estado de insistir en intercambios de favores de infractores. 
las relaciones de simbiosis conveniente que lo protegían (Paxman, 2017). Entre 1938, cuando Jenkins construyó sus primeros cines con Espinosa y Alarcón, y 1941, para cuando había establecido un monopolio de exhibición en el estado, Puebla fue gobernado por Maximino Ávila Camacho, cuya campaña electoral había sido ampliamente financiada por Jenkins. Se creía, además, que Maximino tenía acciones en los cines de Alarcón. En otras palabras, los favores prestados al gobernador le redituaron a Jenkins una inmunidad local de la ley antimonopolios y también protecciones para su negocio azucarero de obreros radicalizados y agraristas armados (Paxman, 2016).

El nexo Jenkins-Maximino y los monopolios locales en cines y azúcar que sostuvo se veían consolidados por el corporativismo, pues el gobernador tuvo a un solo interlocutor en ambos casos. Esto fue políticamente útil: los cines eran conductos para propaganda noticiera que alcanzó a una proporción mucho más grande de la población que los periódicos del estado, y el sector azucarero era de gran importancia en cuanto al empleo, ingresos para el erario y la canasta básica. El nexo en favor de los monopolios se vio favorecido aún más por el personalismo gubernamental. Jenkins y Maximino se reunieron con frecuencia e intercambiaron varios favores financieros (Quintana, 2011; Paxman, 2016).

Dinámicas similares de simbiosis conveniente y personalismo continuaron a nivel nacional. En 1939, Jenkins conoció a Manuel, hermano menor de Maximino, al inicio de su campaña para la presidencia, en una cena privada. Procedió a prestar a Manuel 400000 dólares para ayudarle con sus gastos de campaña, un monto especialmente útil dado que la elección de 1940 resultaría sumamente disputada. En 1945, se reportó que los magnates del azúcar (sin duda incluyendo a Jenkins) hicieron un gran donativo colectivo a la campaña de Alemán. También existe la probabilidad de que ambos presidentes hayan sido accionistas secretos en los cines del Grupo Jenkins. Supuestamente Ávila Camacho recibió algunos de los activos de su hermano Maximino cuando este murió en 1945; al salir de la presidencia era un hombre muy rico. En cuanto a Alemán, su fama de enriquecimiento, en mancuerna con varios prestanombres, era ya bien conocida cuando fue presidente. Después, Jenkins seguía reuniéndose con él — tal como una vez confió en una carta a su familia, para «arreglar» sus «asuntos»—- (Niblo, 1999; Paxman, 2016).

El corporativismo ayuda a explicar cómo el Estado nutrió y protegió el monopolio. Esto se nota especialmente en los sexenios de Ávila Camacho - cuando el Grupo Jenkins fue acusado primero de prácticas monopólicas y cuando obtuvo una posición preponderante en el Distrito Federal por su compra de la cadena líder COTSA一, 
y de Ruiz Cortines — cuando el Grupo Jenkins sufrió múltiples críticas en la prensa y, no obstante, procedió a completar su monopolio al nivel nacional al comprar al único gran rival que quedaba.

Bajo el gobierno de Ávila Camacho, disputas de alto perfil en una de las fábricas textiles de Jenkins, La Trinidad, y su ingenio, Atencingo, se resolvieron por las autoridades federales en favor de los obreros. En La Trinidad, una huelga de dos años finalmente se levantó en julio de 1944 cuando, tras una amplia cobertura en la prensa, el Estado intervino en la fábrica y contrató de nuevo a todo obrero despedido por la gerencia. En Atencingo, un sindicato afiliado a la CTM logró establecer una sección que sindicalizó al ingenio en febrero de 1946. En julio, el presidente dio luz verde para que la cooperativa que surtía caña al ingenio fuera reconstituida como ente autónomo. Como consecuencia de estas dos maniobras en Atencingo, en tan solo seis meses Jenkins perdió su derecho de dictar condiciones de trabajo tanto a sus empleados como a los cañeros (Ronfeldt, 1973; Paxman, 2016).

Como se ha observado, el sexenio avilacamachista fue un período de elevada inflación y numerosas huelgas, de modo que las demandas urgentes del sector laboral del partido gobernante explican en cierta medida el comportamiento contradictorio del presidente hacia Jenkins. Pero solo en cierta medida porque, en cualquier momento, un presidente tenía una gama de opciones para lograr el apaciguamiento de la CTM y otras confederaciones. Entonces, ¿por qué habría actuado Ávila Camacho en contra de uno de sus aliados más ricos y leales?

La segunda parte de la respuesta consiste en dos dimensiones. En un nivel visible, las disputas de la Trinidad y de Atencingo se dieron entre obreros que habían hecho una larga campaña para lograr un trato más justo, campañas que generaban cobertura mediática y notoriedad pública. Apoyar a los trabajadores en tales casos no solo le dio a tres fuerzas laborales distintas beneficios tangibles, sino que significó para el presidente una infusión importante de capital político en sus tratos generales con los sectores laboral y campesino. En un nivel oculto, parece que existía un toma y daca implícito, por el cual el régimen avilacamachista acordó con Jenkins que le permitiría grandes beneficios en un campo, la industria del cine, a expensas de pérdidas menores en otros campos, las cuales servirían al malabarismo corporativista de Ávila Camacho.

Parece que los cálculos corporativistas también orientaron a Ruiz Cortines en sus tratos con Jenkins. Tras su toma de posesión en diciembre de 1952, su régimen impuso un tope sobre los precios de boletos de cine. Como resultado de este favor 
a las clases trabajadores urbanas, México obtendría una de las tasas más altas de asistencia al cine del mundo. En el largo plazo, el tope de precios disminuiría la rentabilidad del sector de exhibición mientras los costos de operación iban en aumento, sobre todo como consecuencia de la devaluación del peso de abril de 1954. Sin embargo, Ruiz Cortines continuó la tradición presidencial de proteger el dominio del Grupo Jenkins. Cuando la prensa criticó intensamente a Jenkins y sus socios en 1953 por sus prácticas monopólicas y por preferir el cine hollywoodense al nacional en sus pantallas, el Estado respondió no con restricciones sino con un generoso plan de financiamiento para producciones locales; y cuando Jenkins logró controlar el nuevo fondo, el gobierno no hizo nada. En 1957, cuando el Grupo Jenkins adquirió al único rival que le quedaba, la cadena del noroeste de Abelardo L. Rodríguez, nuevamente el gobierno no respondió (Paxman, 2016).

Después de más de 15 años de protestas de la industria cinematográfica sobre las prácticas del Grupo Jenkins, el gobierno finalmente actuó. El presidente Adolfo López Mateos expropió sus activos principales en 1960. Se trataba de 365 cines, solo una cuarta parte de lo que controlaba el Grupo, pero eran sus salas más lucrativas, enteramente controladas por COTSA y la Cadena de Oro. Sin embargo, la decisión no significó un castigo tan drástico para Jenkins como le pudo haber parecido al público. Ocho años de precios congelados habían dañado cada vez más los márgenes de utilidad y el Estado continuaría pagando rentas a Jenkins por los edificios de los teatros. El estadounidense tenía ya 82 años y enfocaba su atención en la filantropía y una nueva plantación de algodón en Michoacán (Paxman, 2016). Además Jenkins -y esto probablemente influyó el cálculo del régimen-, a diferencia de casi todos los magnates mexicanos, no tenía una dinastía empresarial familiar que proteger.

\section{Caso 2: La familia Azcárraga y la televisión}

La familia Azcárraga entró el sector de la radiodifusión en 1930, cuando Emilio Azcárraga Vidaurreta fundó XEW-Radio. Este activo constituyó la piedra angular de la empresa Radio Programas de México, cadena líder en la década de 1940 por ser propietaria o arrendataria de la mitad de las estaciones en el país (Mejía Barquera, 1989; Saragoza, 1991). Sin embargo, fue en la industria televisiva, iniciada a principios de los años cincuenta, donde Azcárraga desarrolló una preponderancia monopólica de manera más plena y de mayor duración. 
En 1948 y 1955, los presidentes Alemán y Ruiz Cortines tomaron decisiones sobre la televisión mexicana que, de manera conjunta, formarían al sector durante el resto del siglo XX. La primera fue que la industria debió establecerse no como empresa pública, como la BBC de Gran Bretaña, sino según lineamientos comerciales, como en Estados Unidos. La segunda fue que se le permitiera a las tres estaciones capitalinas que se lanzaron en 1950, 1951 y 1952, pertenecientes respectivamente al industrial poblano Rómulo O’Farrill, al magnate de radio (y cine) Azcárraga Vidaurreta y al inventor Guillermo González Camarena, fusionarse como empresa única, bajo el pretexto de las pérdidas financieras de las tres. Así, en conjunto, los dos presidentes establecieron la televisión como monopolio privado, lo que perduraría (excepto por un breve segundo experimento con la competencia) hasta 1993 (Saragoza, 1991; Fernández y Paxman, 2013).

La primera decisión incorporaba claramente una simbiosis conveniente. ${ }^{6}$ Que la televisión se estableciera como negocio privado le permitió a Alemán otorgar a su amigo O'Farrill la primera licencia televisiva (Canal 4), tomar él mismo acciones en la empresa y favorecerla con varias ventajas. Para mantener apariencias democráticas, Alemán le dio una segunda licencia (Canal 2) al más experimentado empresario, Azcárraga. Pero luego debilitó la operación de Azcárraga al otorgar una tercera licencia a su principal ingeniero, González Camarena (Saragoza, 1991).

La segunda decisión, que trataba de la fusión, también trajo el sello distintivo de la conveniencia. Ruiz Cortines - que debió su ascenso a la presidencia a Alemán, con quien llevaba amistad desde que los dos iniciaron sus careras políticas en Veracruz en los años treinta - probablemente aprobó la fusión, en parte, para asegurar que Alemán se beneficiara de su inversión encubierta, la cual había estado en peligro. En 1955, el Canal 4, al que le faltaba el acervo de talento del Canal 2, todavía registraba pérdidas sustanciales, tanto que fue O'Farrill quien propuso la fusión a Azcárraga. La admisión de necesidad de O'Farrill le dio a Azcárraga el mando de Telesistema Mexicano (TSM), como se nombraría el ente combinado (Saragoza, 1991). La familia Alemán sería accionista importante en TSM, renombrado Televisa en 1973, hasta que vendió sus acciones en 1999 (Preston, 1999: 4).

\footnotetext{
${ }^{6}$ Este no fue el único factor. Mientras la mayoría de los intelectuales preferían el modelo público, la radio se había establecido en los años veinte y treinta principalmente como negocio privado, así que ya se había sentado un precedente (Mejía Barquera, 1989).
} 
Adicionalmente, se puede considerar que la fusión fue conveniente, y no necesaria, a la luz de su naturaleza única. En las grandes economías sudamericanas, en donde la televisión debutó más o menos al mismo tiempo que en México, los problemas de altos costos y un lento crecimiento de ingresos no fueron pretexto para permitir una fusión monopólica entre rivales privados. En Venezuela, la competencia se formó entre Radio Caracas Televisión (RCTV) y Venevisión, que perduraría durante medio siglo. La rivalidad también surgió en Brasil, al inicio entre TV Tupi y Rede Globo, y luego entre Globo y tres o cuatro redes más (Sinclair, 1999).

Pero la fusión también reflejó un nivel de simbiosis imperativa. Para la presidencia de Ruiz Cortines, el PRI se consolidaba como el partido gobernante hegemónico. No obstante, la cúpula del PRI todavía tenía mucho de qué preocuparse (Gillingham y Smith, 2014). Una facción separatista del PRI había disputado ferozmente la elección de 1952, hubo episodios de violencia durante y después de la campaña y ningún candidato oficial había obtenido un porcentaje tan relativamente bajo del voto como el 74 \% de Ruiz Cortines. La convención anual del PRI de 1953 generó titulares sobre el grado inusual de abierta disidencia (Niblo, 1999: 237). En algunos estados, entre ellos Puebla, el Estado de México y San Luis Potosí, los cacicazgos locales —no el presidente-imponían todavía su selección de gobernador y decidieron cuáles políticas federales se cumplirían y cuáles no (Hernández Rodríguez, 2014).

Sobre todo, México todavía era un país geográfica y culturalmente fragmentado, en el cual la mitad de la población era analfabeta y el sentido compartido de mexicanidad era limitado. Fomentar el crecimiento de la televisión al permitir la fusión, para que cada vez más mexicanos pudieran ver sus programas de variedades, que llevaban géneros musicales regionales a una audiencia nacional, y sus noticieros, que siempre alababan al gobierno, podría ayudar a unir la nación e instilar una reverencia al presidente y al partido como nunca antes (González de Bustamante, 2015). Las economías de escala propiciadas por la fusión permitirían a TSM expandirse por todo el país - por medio de estaciones subsidiarias, filiales y repetidoras - con más rapidez que cualquiera de las estaciones originales solas. Así, Ruiz Cortines obtuvo una plataforma mejorada de propaganda para complementar las plataformas principales de los noticieros radiofónicos y cinematográficos.

En cuanto a la industria de la TV, se trataba de un negocio intensivo en capital, tanto para arrancar como para expandirse geográficamente. Azcárraga y O’Farrill todavía sufrían pérdidas cuantiosas debido a que los mexicanos compraban televisores a un ritmo mucho más lento que los estadounidenses, así que los anunciantes estuvieron renuentes a comprometerse con el nuevo medio; para 1955, solo 3 \% de los 
hogares mexicanos tenían un aparato de televisión (González de Bustamante, 2015). Además, la devaluación del peso de 1954 incrementó sustancialmente el costo de la programación y de los equipos importados.

La interdependencia e intercambio de favores influyeron en las relaciones entre el Estado y la industria televisiva de ese momento en adelante. En 1960, al determinar que México todavía no estaba lo suficiente interconectado, el régimen de López Mateos inauguró un Sistema Nacional de Microondas, que transmitiría señales telefónicas y televisivas en los lugares más remotos del terreno montañoso mexicano. Esta inversión de infraestructura representó un gran subsidio a TSM, pero se hacía más por conveniencia que por necesidad, porque la televisión ya estaba cerca de alcanzar una masa crítica de consumidores, con televisores en 780000 hogares (Fernández y Paxman, 2013; González de Bustamante, 2015).

También en 1960, el gobierno promulgó una ley de radiodifusión que finalmente se centró en la televisión tanto como en la radio. Entre otras cuestiones, se consideró necesario regular el contenido televisivo para que no ofendiera las buenas costumbres. Esto sí se hizo, pero como favor a Azcárraga se permitió al propio TSM autocensurarse (Fernández Christlieb, 1982). El segundo favor fue que las demandas de críticos para que el Estado limitara la cantidad de programas importados de Estados Unidos y otros países no rindieran fruto. El tercer favor fue que López Mateos rechazara las solicitudes de licencias televisivas capitalinas de otros inversionistas ansiosos de entrar a la industria en expansión. Esta política le sirvió tanto al Estado como a TSM. De nuevo, como partido corporativista, el PRI encontró conveniente que TSM fuera el único interlocutor y propagandista (González de Bustamante, 2015).

En 1967, sin embargo, tras presiones de la iniciativa privada, el régimen de Gustavo Díaz Ordaz otorgó dos nuevas licencias televisivas; las nuevas redes se estrenaron en 1968. Pero ambos, Díaz Ordaz y su sucesor, Luis Echeverría, se hicieron de la vista gorda cuando Azcárraga, ayudado por su hijo, Emilio Azcárraga Milmo, utilizaron todo tipo de prácticas monopólicas para obstaculizar a los nuevos rivales. Estas incluyeron boicots a los anunciantes y a las estrellas que se atrevieran a salir en los canales de la competencia. En 1972 -en una especie de repetición de lo que sucedió en 1955- Echeverría permitió la fusión entre TSM y su competidor principal, TIM. La nueva empresa emergió en 1973 como Televisa (Fernández y Paxman, 2013).7

\footnotetext{
7 Luego, en 1973, Echeverría nacionalizó la segunda nueva emisora (Canal 13), que había quedado en manos de un banco estatal tras declararse en bancarrota.
} 
Echeverría, el presidente izquierdista-populista-nacionalista, y Azcárraga Milmo, el magnate conservador proestadounidense, no se llevaban bien. Entonces, ¿por qué Echeverría, que pondría a muchas empresas privadas en manos del Estado, no procedió en 1972 con la amenaza de nacionalizar TSM y TIM? La respuesta comporta un reconocimiento pragmático de necesidades mutuas, nuevamente la simbiosis imperativa. La amenaza de Echeverría de nacionalizar la industria televisiva recordó a Azcárraga de su dependencia, como concesionario, de la buena voluntad del Estado; de este modo, trató de apaciguarlo con mejores programas. Y desde la perspectiva del presidente, los Azcárraga eran magnates de los medios muy capaces. Sus telenovelas, conservadoras en el aspecto social, eran ampliamente vistas como el opio popular. El noticiero nocturno, renacido en 1970 como 24 horas, con Jacobo Zabludovsky, su locutor servil, llevaría la imagen y las declaraciones del presidente a más mexicanos que si la empresa se le encargara a unos burócratas. Y dada su conocida complicidad con la masacre de Tlatelolco de 1968, Echeverría, el PRI y el Estado en general necesitaban mejorar su imagen tan eficazmente como fuera posible (Krauze, 1996; Fernández y Paxman, 2013; González de Bustamante, 2015).

Durante la mayor parte del cuarto de siglo subsecuente, hasta que muriera Azcárraga Milmo en 1997, Televisa desempeñó un rol sumamente visible como el ministerio de propaganda no oficial y como los «soldados del PRI». Esta etiqueta teatral implicaba la subordinación, pero a la vista de muchos había un nexo más o menos entre iguales: un monopolio político que operaba en simbiosis con un monopolio mediático (Trejo Delarbre, 1985; Lawson, 2002). Esa interdependencia nunca fue más visible que en 1988, cuando el candidato del PRI, Carlos Salinas, casi perdió la elección presidencial. Lo que decidió y consolidó el resultado fue una combinación de fraude electoral y propaganda de Televisa (Trejo Delarbre, 2001).

A cambio, Salinas repitió la taimada táctica de apertura de medios de Díaz Ordaz. Como resultado de presiones privadas - que ahora se habían intensificado por el inicio de las pláticas sobre un Tratado de Libre Comercio de América del Norte (TLC), lo que Salinas necesitaba mostrar a Estados Unidos y Canadá era que la suya era una nación moderna que acogía la competencia- en 1990 el presidente anunció la venta de la paraestatal Imevisión; esto restauraría la competencia privada en el ámbito televisivo. Pero luego demoró la subasta durante tres años, y después se hizo de la vista gorda cuando Azcárraga revivió las viejas amenazas monopolísticas a sus anunciantes y estrellas, para garantizar que la nueva televisora, TV Azteca, tuviera un comienzo lento. De manera parecida, la Comisión Federal de Competencia, que era el órgano regulador de monopolios recién creado por Salinas, rehusó examinar 
Televisa. Además, el presidente compensó a Azcárraga, a quien se le prohibió competir en la subasta de Azteca, otorgándole a Televisa 62 concesiones provinciales con las cuales tenía la posibilidad de crear una cuarta red nacional. Así, una combinación de indulgencia presidencial, nuevas concesiones, una serie de favores menores y el gran auge publicitario asociado con la inminencia del TLC, ayudaron a Azcárraga a encabezar la lista Forbes de multimillonarios latinoamericanos en julio de 1993 (Fernández y Paxman, 2013).

La cercanía ideológica de Azcárraga con Salinas, el acogimiento personalista del presidente al magnate - viajaron juntos varias veces a Estados Unidos, los fotografiaron viéndose muy amistosos- cimentó el nexo entre ellos. Estos factores también alimentaron la idea de que Azcárraga era uno de los grandes beneficiarios del amiguismo de la época. ¿Será que el juicio es verídico? No hay evidencia de que ni Salinas ni otro priista de alto rango se beneficiara económicamente de su relación con Azcárraga. Tampoco Azcárraga dependía de los favores de Salinas para que su negocio fuera exitoso. Las utilidades de Televisa y la riqueza de primera liga de Azcárraga debían mucho más al desarrollo emprendedor de un formato de entretenimiento, la telenovela, que la compañía había producido durante 35 años.

Lo que sí existió fue una simbiosis imperativa, que motivaba al Estado y al conglomerado a un nivel institucional. Como cada régimen desde el de Ruiz Cortines, el gobierno salinista necesitaba a Televisa para mejorar su imagen tras el fraude de 1988, moldear las tendencias en las urnas, fomentar el apoyo público al TLC y ofrecer entretenimiento escapista e inspirado en el darwinismo social, que cumpliría la misma función que la del Cine de Oro: complacer a la población y animar a cada clase social a conocer su lugar. Y Televisa dependía del Estado: para renovar automáticamente sus concesiones de radiodifusión, proteger su cuasimonopolio y mantener políticas favorables para la actividad empresarial.

\section{Conclusión: dos monopolios, hilos comunes}

El 23 de febrero de 1993, Azcárraga participó en un evento que reflejaba los cuatro factores del monopolio mexicano considerados aquí, cuando junto con 28 magnates más asistió a una cena de recaudación de fondos para el PRI, en la casa del exsecretario de Hacienda, Antonio Ortiz Mena. Genero Borrego, presidente del partido, le pidió a cada uno la promesa de 25 millones de dólares para las campañas electorales de 1994. El personalismo presidencial fue claro con la presencia de Salinas, quien 
asistió para ayudar a engatusar a los invitados. El corporativismo fue evidente por el hecho de que cada invitado, con la excepción de una media docena de banqueros prominentes, era monopolista o duopolista, representante real de un sector industrial; la invitación significó la aprobación estatal de su preponderancia sectorial y la creencia del PRI en que cada sector era lo suficientemente redituable para que una petición de 25 millones de dólares resultara factible. ${ }^{8}$ La conveniencia de la simbiosis fue evidente en que fueron los líderes del partido quienes pidieron los fondos, lo que en caso de que hubiera un triunfo electoral mejoraría las perspectivas políticas de Borrego y el prestigio global de Salinas, y en la expectativa de que los donadores - la mayoría de los cuales ya se había beneficiado del programa de privatizaciones de Salinas - gozarían de más favores. ${ }^{9}$ Al final, la simbiosis imperativa fue evidente en la necesidad del gobierno de fortalecer la distinción entre este y el partido, para cumplir la promesa de Salinas a Washington y Ottawa (en el contexto de sus autorizaciones pendientes del TLC) de que México se estaba democratizando; así, entre otras cosas, el PRI ya no financiaría sus campañas desde el erario. Mientras tanto, la mayoría de la iniciativa privada creía que el neoliberalismo era el único camino; no podían arriesgar que la izquierda mejorara el desempeño que tuvo en 1988.

Es posible que los monopolios de cine y TV sean, de cierto modo, anómalos, en el sentido en que la interdependencia de Jenkins y los Azcárraga con el Estado estuvo caracterizada, en parte, por servicios propagandísticos que los magnates de otros sectores no podían ofrecer. La cena en casa de Ortiz Mena, no obstante, sugiere que la clase dirigente consideró a los capitanes de la industria en su conjunto, sin importar el sector al que pertenecían, como aliados naturales, una alianza que data de los años veinte, cuando el régimen posrevolucionario necesitaba capacidades como la creación de empleos, el pago de impuestos y la ayuda con préstamos internacionales de los magnates de la época; y los magnates a su vez necesitaban protecciones y garantías del Estado. Dicho esto, hace falta investigar más para determinar la naturaleza exacta de las relaciones características de las empresas privadas más grandes y el Estado, y cómo estas evolucionaron a lo largo de los sexenios.

8 Además de Azcárraga, los invitados incluyeron a Jerónimo Arango (supermercados), Alberto Bailleres (minería), Bernardo Garza Sada (acero), Claudio X. González (papel), Jorge Larrea (minería), Ángel Losada (supermercados), Jorge Martínez Guitrón (acero), Adrián Sada (vidrio), Carlos Slim (telefonía), Lorenzo Zambrano (cemento). (Rodríguez Castañeda, 1993: 6-9).

${ }_{9}$ Al final de la cena, muchos invitados le pidieron favores de intercambio a Salinas (Scherer, 1995: 29-30). 
De las evidencias presentadas aquí, pueden extraerse varias deducciones sobre la prevalencia del monopolio en el México moderno. Primero, la época posrevolucionaria fue un período fértil para el establecimiento de monopolios en potencia, ya que un Estado que necesitaba consolidar su poder tras diez años de guerra civil buscaba potencias del sector privado con quienes construir apoyos mutuos. Esta dinámica se desenvolvió tanto en provincia como en el ámbito nacional. Segundo, las décadas de 1940 y 1950 fueron un tiempo propicio para el desarrollo monopólico, porque el gobierno estaba ya en manos de políticos que ideológicamente favorecían la empresa privada y, en lo personal, se interesaban en inversiones encubiertas, a diferencia de la toma forzosa de activos que habían favorecido muchos políticos de los años veinte y treinta. Tercero, a partir de 1938, la cultura política corporativista complementaba estas tendencias, ya que a los líderes de México les convenía tener a un solo interlocutor por sector; les fue conveniente no únicamente por propósitos propagandísticos (por medio del cine y la TV) sino de forma más amplia para equilibrar intereses con los de la CTM, porque un fallo en contra de un magnate (tangible o simbólico) podía declararse como una victoria para los obreros en general. Cuarto, el personalismo presidencial llevó a que en muchos casos se tratara a tales interlocutores como amigos, y las amistades suponen aún más intercambios de favores.

También pueden hacerse varias deducciones sobre la naturaleza del monopolio, en México y en otras latitudes. Primero, algunos monopolios tienen orígenes locales, en vez de nacionales, por ejemplo en Puebla o la Ciudad de México. Esto significa que las protecciones políticas pueden originarse no con políticos federales sino con gobernadores. Segundo, el equilibrio simbiótico puede cambiar durante el tiempo. En 1955, O'Farrill y Azcárraga necesitaban a Ruiz Cortines y su aprobación de una fusión más de lo que el presidente los necesitaba a ellos (ya que la TV todavía era una plataforma propagandística modesta en relación con la radio o los cines). Por otro lado, Salinas necesitaba más a Televisa que esta al presidente en los tiempos electorales de 1988 (una dinámica que se repetiría con el candidato Enrique Peña Nieto en 2012). Esto implica que la tendencia a veces expresada en la prensa mexicana de calificar a una parte como títere de la otra es, como mucho, una opinión de corto plazo.

Traducción del inglés: Luis Barrón. 


\section{Referencias bibliográficas}

Águila, M., Soler M. y Suárez R. (2007). Trabajo, Fortuna y Poder. Manuel Espinosa Yglesias, un empresario mexicano del siglo XX. México: CEEY.

Aguilar M., A. y Carmona, F. (1967). México. Riqueza y miseria. México: Nuestro Tiempo. Ávila Camacho, M. (1946). Ávila Camacho al Congreso, «Ley que crea la Comisión para el Fomento de la Cinematografía Nacional», 17/i/1946, Archivo General de la Nación, Manuel Ávila Camacho, Exp. 201.1/5.

Basáñez, M. (1981). La lucha por la hegemonía en México, 1968-1980. México: Siglo XXI. Bortz, J. y Haber, S., coords. (2002). The Mexican Economy, 1870-1930. Stanford, California: Stanford University Press.

Camp, R. A. (1989). Entrepreneurs and Politics in Twentieth-Century Mexico. Nueva York: Oxford University Press, 1989.

Ceceña, J.L. (1963). El capital monopolista y la economía de México. México: Cuadernos Americanos.

Cerutti, M. (1999). «Regional Studies and Business History in Mexico since 1975». En Dávila, C. y Miller, R. (coords.). Business History in Latin America. Liverpool: Liverpool University Press.

Concheiro, E., Gutiérrez, A. y Fragoso, J.M. (1979). El poder de la gran burguesía. México: Cultura Popular.

Cosío Villegas, D. (1972). El sistema político mexicano. México: Joaquín Mortiz.

Deans-Smith, S. (1992). Bureaucrats, Planters, and Workers: The Making of the Tobacco Monopoly in Bourbon Mexico. Austin: University of Texas Press.

Espinosa Yglesias, M. (2000). Bancomer. Logro y destrucción de un ideal. México: Planeta.

Fernández, C. y Paxman A. (2013). El Tigre. Emilio Azcárraga y su imperio Televisa. México: Grijalbo.

Fernández Christlieb, F. (1982). Los medios de difusión masiva en México. México: Juan Pablos.

Garrido, L.J. (1989). "The Crisis of Presidencialismo». En Cornelius, W.A., Gentleman, J. y Smith, P.H., coords. Mexico's Alternative Political Futures. La Jolla, California: Center for U.S.-Mexican Studies.

Gillingham, P. y Smith, B.T., coords. (2014). Dictablanda: Politics, Work, and Culture in Mexico, 1938-1968. Durham, N.C.: Duke University Press.

González de Bustamante, C. (2015). «Muy buenas noches». México, la televisión y la Guerra Fría. México: Fondo de Cultura Económica.

Haber, S. (1989). Industry and Underdevelopment. Stanford, California: Stanford University Press. 
Haber, S. (coord.) (1997). How Latin America Fell Behind: Essays on the Economic Histories of Brazil and Mexico. Stanford, California: Stanford University. Press.

Haber, S., coord. (2002). Crony Capitalism and Economic Growth in Latin America. Stanford, California: Hoover Press.

Haber, S., Razo, A. y Maurer, N. (2003). The Politics of Property Rights. Cambridge: Cambridge University Press.

Hamilton, N. (1982). The Limits of State Autonomy. Princeton, N.J.: Princeton University Press.

Hernández Rodríguez, R. (2014). «Strongmen and State Weakness». En Gillingham, P. y Smith, B.T., coords., Dictablanda: Politics, Work, and Culture in Mexico, 19381968. Durham, N.C.: Duke University Press.

Jacobo, E., Luna, M. y Tirado, R. (1989). Empresarios de México. Aspectos económicos e ideológicos. Guadalajara: Universidad de Guadalajara.

Krauze, E. (1996). La presidencia imperial. México: Tusquets.

Lawson, C. (2002). Building the Fourth Estate: Democratization and the Rise of a Free Press in Mexico. Berkeley: University of California Press.

Leal, J.F. (1972). La burguesía y el Estado mexicano. México: El Caballito.

Ley Federal de Competencia Económica, LFCE, 1992.

Ley Federal de Competencia Económica, LFCE, 2006.

Ley Orgánica del Artículo 28 Constitucional en materia de Monopolios (1934).

Martínez Nava, J. M. (1984). Conflicto Estado-empresarios en los gobiernos de Cárdenas, López Mateos y Echeverría. México: Nueva Imagen.

Maurer, N. (2002). The Power and the Money. Stanford, California: Stanford University Press.

Mejía Barquera, F. (1989). La industria de la radio y la televisión y la política del Estado mexicano (1920-1960). México: Fundación Manuel Buendía.

Middlebrook, K. (1995). The Paradox of Revolution. Baltimore: Johns Hopkins University Press.

Monsiváis, C. (1994). «Vino todo el pueblo y no cupo en la pantalla». En Monsiváis, C. y Bonfil, C. A través del espejo. México: El Milagro.

Morris, S. (1991). Corruption and Politics in Contemporary Mexico. Tuscaloosa: University of Alabama Press.

Niblo, S. (1995). War, Diplomacy, and Development. Wilmington: SR Books.

Niblo, S. (1999). Mexico in the 1940s. Wilmington: SR Books.

Noble, A. (2005). Mexican National Cinema. London: Routledge.

Organización para la Cooperación y el Desarrollo Económicos, OCDE (2017). Estudio de la OCDE sobre telecomunicaciones y radiodifusión en México 2017. París: OECD. https://doi.org/10.1787/9789264280656-es 
Ortiz Rivera, A. (1997). Juan Sánchez Navarro. México: Grijalbo.

Paxman, A. (2016). En busca del señor Jenkins. México: Debate/CIDE.

Paxman, A. (2017). «Simbiosis imperativa y conveniente: la evolución del capitalismo de cuates en Puebla, 1920-1940». Istor 68.

Pérez Miranda, R. (1999). Propiedad industrial y competencia en México. México: Porrúa.

Preston, J. (7 de abril de 1999). «One Family Exits Mexican TV Empire», The New York Times.

Quintana, A. (2011). Maximino Ávila Camacho y el Estado unipartidista. Puebla: Ediciones de Educación y Cultura.

Rodríguez Castañeda, R. (8 de marzo 1993). «Borrego, 29 magnates y el presidente de la República». Proceso 853: 6-9.

Romero Ibarra, M.E., Contreras Valdez J.M. y Reyes Méndez J.. coords. (2006). Poder público y poder privado. Gobierno, empresarios y empresas, 1880-1980. México: UNAM.

Ronfeldt, D. (1973). Atencingo: The Politics of Agrarian Struggle in a Mexican Ejido. Stanford, California: Stanford University Press.

Saragoza, A. (1988). The Monterrey Elite and the Mexican State, 1880-1940. Austin: University of Texas Press.

Saragoza, A. (1991). «Behind the Scenes: Media Ownership, Politics, and Popular Culture in Mexico (1930-1958)». En Camp, R, Hale, C. y Vásquez, J. (coords.), Los intelectuales y el poder en México. México: Colegio de México.

Scherer García, Julio (1995). Estos años. México: Océano.

Sinclair, J. (1999). Latin America Television. Nueva York: Oxford University Press.

Story, D. (1986). Industry, The State, and Public Policy in Mexico. Austin, Texas: University of Texas Press.

Trejo Delarbre, R., coord. (1985). El Quinto Poder. México: Claves Latinoamericanas.

Trejo Delarbre, R. (2001). Mediocracia sin mediciones. México: Cal y Arena.

Valdés Ugalde, F. (1997). Autonomía y legitimidad. México: Siglo XXI.

Wasserman, M. (1993). Persistent Oligarchs. Durham, N.C.: Duke University Press. 


\section{Sobre el autor}

Andrew Paxman nació en Londres, Inglaterra, y es profesor de historia y periodismo en el Centro de Investigación y Docencia Económicas, CIDE. Es coautor de El Tigre. Emilio Azcárraga y su imperio Televisa y autor de una biografía del magnate William Jenkins, titulado En busca del señor Jenkins: dinero, poder y gringofobia en México. Su publicación más reciente es el libro que coordinó, Los gobernadores: caciques del pasado y del presente. Su próximo libro (en proyecto) es la historia reciente de la prensa mexicana, desde 1988 hasta nuestros días.

andrew.paxman@cide.edu

https://orcid.org/0000-0001-6489-4881 